\title{
Photodegradation of Phenol over a Hybrid Organo-Inorganic Material: Iron(II) Hydroxyphosphonoacetate
}

\author{
Montse Bazaga-Garcia, Aurelio Cabeza, Pascual Olivera-Pastor, Isabel Santacruz, Rosario M. P. Colodrero, \\ and Miguel A. G. Aranda*
}

Departamento de Química Inorgánica, Universidad de Málaga, Campus Teatinos s/n, 29071-Málaga, Spain

\section{Supporting Information}

ABSTRACT: Water treatment is a hot topic, and it will become much more important in the decades ahead. Advanced oxidation processes are being increasingly used for organic contaminant removal, for example using photoFenton reactions. Here we report the use of an organo-inorganic hybrid, $\mathrm{Fe}\left[\mathrm{HO}_{3} \mathrm{PCH}(\mathrm{OH}) \mathrm{COO}\right] \cdot 2 \mathrm{H}_{2} \mathrm{O}$, as Fenton photocatalyst for phenol oxidation with $\mathrm{H}_{2} \mathrm{O}_{2}$ under UVA radiation. Preactivation, catalyst content, and particle size parameters have been studied/optimized for increasing phenol mineralization. Upon reaction, iron species are leached from the catalyst making a homogeneous catalysis contribution to the overall phenol photo-oxidation. Under optimized conditions, the mineralization degree was slightly larger than $90 \%$ after $80 \mathrm{~min}$ of irradiation. Analysis by X-ray photoelectron spectroscopy revealed important chemical modifications occurring on the surface of the catalyst after activation and phenol photodegradation. The sustained slow delivery of iron species upon phenol

photoreaction is advantageous as the mixed heterogeneous-homogeneous catalytic processes result in very high phenol mineralization.

\section{INTRODUCTION}

Metal-organic frameworks (MOFs) represent an expanding class of crystalline hybrid organic/inorganic solids, possessing a rich variety of structures and associated physicochemical properties. The structural and functional versatility of these compounds derives from the chemical synergy between an inorganic component, consisting of single cations or small discrete clusters, and multidentate organic linkers. Recent advances in MOF synthesis have provided a bunch of materials with specific structural features for applications such as gas absorbers, catalysts, or sensors. ${ }^{1}$ For some functionalities, the organic linker has been shown to be determinant in key characteristics such as porosity, structural flexibility and the responsive character to stimuli. In other compounds, the metal is central for the most relevant properties of targeted applications but importantly aided by some properties of the organic component. So, MOF-5, considered as a microporous semiconductor, is composed of discrete semiconductor $\mathrm{Zn}_{4} \mathrm{O}_{13}$ quantum dots interconnected by terephthalate linkers. It exhibits activity as photocatalyst and the linker itself enhances this activity by absorbing the light and sensitizing the semiconductor dots. ${ }^{2}$ In addition, remarkable photophysical properties have been highlighted for lanthanide-based metalorganic frameworks (Ln-MOFs), with the organic component acting as antennae of light. ${ }^{3}$ In particular, Eu-MOFs were reported as efficient photocatalysts. ${ }^{4}$ Even more, some $\mathrm{Ru}$ MOFs compounds have been found to be active for the chemical reduction of water. ${ }^{5}$ The most common and widely

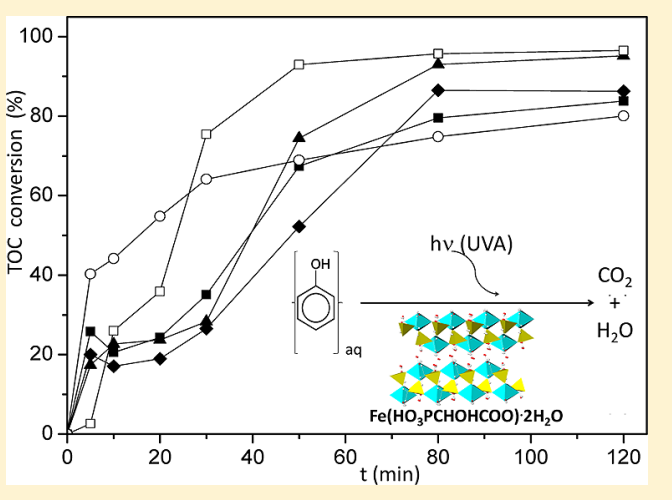

studied MOFs materials are those based on carboxylate ligands. However, hybrid organo-inorganic compounds based on that metal-ligand linkage are not very stable, mainly in water. Hence, MOFs based-phosphonates are being increasingly researched as their chemical stabilities are larger. ${ }^{3,6,7}$

On the other hand, Fenton chemistry is a well-known example of advanced oxidation processes (AOPs) for organic contaminant destruction. ${ }^{8,9}$ It is based on reactions of hydrogen peroxide in the presence of iron to generate highly reactive species, useful for cleaning biologically toxic or nonbiodegradable substances in water. Combined with UV irradiation the process is enhanced by photo-Fenton reactions, ${ }^{10,11}$ due to a series of photochemical reactions leading to a more efficient $\mathrm{Fe}(\mathrm{II})$ recycling. As previously demonstrated in homogeneous catalysis, chelated iron, mainly by carboxylate groups, may substantially improve the mineralization rate of organic pollutants. However, when used in homogeneous catalysis, $\mathrm{Fe}$ (II) salts can be considered as reactants as they are very expensive to recover. So, there is increasing interest in using heterogeneous catalysis for these applications. ${ }^{12,13}$ There is little work on metal phosphonate hybrid materials used for AOPs studies, and to the best of our knowledge, they are always based on titanium derivatives. ${ }^{14}$

Received: May 3, 2012

Revised: June 20, 2012

Published: June 20, 2012 
Thus, we have undertaken the study of the photocatalytic behavior of an hybrid organo-inorganic iron(II) hydroxyphosphonoacetate, $\mathrm{Fe}\left[\mathrm{HO}_{3} \mathrm{PCH}(\mathrm{OH}) \mathrm{CO}_{2}\right] \cdot 2 \mathrm{H}_{2} \mathrm{O}$, under different conditions. This compound has been previously reported to have a layered structure and several divalent metal hybrids crystallize in that structure type. ${ }^{15,16}$ Iron was chosen due to its photo-Fenton properties and wide availability. 2-Hydroxyphosphonoacetic acid was selected because of its chemical stability, relative low carbon content, the fact that possible photodegradation products are not toxic, and, last but not least, low cost. The degradation of phenol was used as a standard probe. ${ }^{17,18}$ This substance is one of the most studied pollutants because of its high toxicity and large presence in industrial wastewater.

\section{EXPERIMENTAL SECTION}

2.1. Materials. Iron(II) sulfate heptahydrate, sodium fluoride, and phenol were purchased from Sigma-Aldrich; $33 \%$ hydrogen peroxide and 37\% hydrochloric acid from Prolabo; acetic acid from Probus; 4-amino-antipyrine from Fluka Analytical; and 50\% v/v hydroxyphosphonoacetic acid (HPAA: $\mathrm{CH}(\mathrm{OH})\left(\mathrm{CO}_{2} \mathrm{H}\right)\left(\mathrm{PO}_{3} \mathrm{H}_{2}\right)$ ) from BioLab. $\mathrm{TiO}_{2} \mathrm{P} 25$ was purchased from Degussa.

2.2. Synthesis of FeHPAA. The synthesis of $\mathrm{Fe}\left[\mathrm{HO}_{3} \mathrm{PCH}-\right.$ $\left.(\mathrm{OH}) \mathrm{CO}_{2}\right] \cdot 2 \mathrm{H}_{2} \mathrm{O}, \mathrm{FeHPAA}$, has been previously reported. ${ }^{15} \mathrm{~A}$ mixture of $\mathrm{FeSO}_{4} \cdot 7 \mathrm{H}_{2} \mathrm{O}(2.8691 \mathrm{~g}, 10.3 \mathrm{mmol}), \mathrm{NaF}(1.5686 \mathrm{~g}$, $37.3 \mathrm{mmol})$, HPAA solution $(4.14 \mathrm{~mL}, 18.5 \mathrm{mmol}), 7.52 \mathrm{~mL}$ of acetic acid, and $30.08 \mathrm{~mL}$ of deionized water was transferred to a Teflon-lined autoclave and heated to $140{ }^{\circ} \mathrm{C}$ for four days. Typically, about $2.4 \mathrm{~g}$ of a solid product consisting of pale yellow crystals was obtained at a final $\mathrm{pH}$ value of 3.0, the yield being approximately $95 \%$ based on the iron salt. The solid is a single crystalline phase according to its powder diffraction pattern.

2.3. Basic Characterization. The catalyst was characterized by powder X-ray diffraction. The patterns were collected on a PANalytical X'Pert Pro diffractometer equipped with an X'Celerator detector. Surface characterization of the catalyst, including the binding energies and the relative concentrations of $\mathrm{Fe}, \mathrm{O}, \mathrm{P}$, and $\mathrm{C}$ was carried out by $\mathrm{X}$-ray photoelectron spectroscopy (XPS). The XPS analyses were performed on a Physical Electronics ESCA 5701 spectrometer with a multichannel hemispherical electron energy analyzer. $\operatorname{MgK} \alpha 300 \mathrm{~W}$, $15 \mathrm{kV}, 1253.6 \mathrm{eV}$ was used as nonmonochromatic source of excitation radiation. The spectrometer energy scale was calibrated using the photoelectronic lines of $\mathrm{Cu} 2 \mathrm{p}^{3 / 2}, \mathrm{Ag}$ $3 \mathrm{~d}^{5 / 2}$ and $\mathrm{Au} 4 \mathrm{f}^{7 / 2}$ at $932.7,368.3$, and $84.0 \mathrm{eV}$, respectively. The high-resolution spectra were recorded at a takeoff angle of $45^{\circ}$ and operating in power constant $29.35 \mathrm{eV}$ step and using an analyzer opening $720 \mu \mathrm{m}$ in diameter. The pressure in the analysis chamber was maintained at $6 \times 10^{-9}$ Torr during acquisition of spectra. Each spectral region was scanned several cycles until a good signal-to-noise ratio was achieved. The software PHI ACCESS ESCA-V8.0C was used for data acquisition. The colloidal stability of the catalyst was analyzed by microelectrophoresis from the variation of the zeta potential $(\zeta)$ as a function of $\mathrm{pH}$. Zeta potential measurements were carried out on a Malvern Zetasizer NanoZS instrument and the $\mathrm{pH}$ on a PC $5000 \mathrm{~L}$ pHenomenal $\mathrm{pH}$-meter. Samples were prepared by suspending the catalyst in deionized water, using a concentration of $220 \mathrm{mg} \mathrm{L} \mathrm{L}^{-1}$. The $\mathrm{pH}$ was adjusted with 1.0 and $0.1 \mathrm{M} \mathrm{HCl}$ and $\mathrm{NaOH}$ stock solutions. Dispersions were ultrasonically homogenized using a $400 \mathrm{~W}$ sonication probe
(UP400s Hielscher Ultrasonics) for $30 \mathrm{~s}$. To study the effect of milling on the final properties, the powder was suspended in 75 $\mathrm{mL}$ of water at a concentration of $700 \mathrm{mg} / \mathrm{L}$, and milled with alumina balls for 2 and $4 \mathrm{~h}$ in a MM200 Retsch vibratory mill. The powders were characterized by Scanning Electron Microscopy (SEM) on a JEOL SM 840 microscope. Specific surface was determined using the single-point BET method (ASAP 2020, Micromeritics, U.S.A).

2.4. Photocatalytic Test and Measurements. The photodegradation experiments were conducted on a Luzchem CCP-4 V photochemical reactor (Luzchem Research) with mechanical stirring during the illumination to ensure a thorough mixing at room temperature as previously reported. ${ }^{19}$ The photoreactor was equipped with six $8 \mathrm{~W}$ black lamps (Hitachi FL8BL-B) that emit UVA in the wavelength range of $300-400 \mathrm{~nm}$, centered at $365 \mathrm{~nm}$. This radiation was selected because (i) its a main component of UV light in the solar spectrum; (ii) its ready availability; and (iii) the photocatalyst shows a high photochemical stability in this wavelength region. Variable amounts of the catalyst $(220,500$, and $700 \mathrm{mg} / \mathrm{L}$ ) were suspended in $1 \mathrm{~L}$ of an aqueous solution containing 50 $\mathrm{mg} / \mathrm{L}$ of phenol. The initial $\mathrm{pH}$ of the suspensions was adjusted with $1 \mathrm{M} \mathrm{HCl}$ or $\mathrm{NaOH}$ stock solutions. In addition to the asprepared suspension, $20 \mathrm{~mL}$ were extracted at 5, 10, 20, 30, 50, 80 , and $120 \mathrm{~min}$ of irradiation and filtered in order to carry out the appropriate analyses.

The mineralization degree of phenol was followed by measuring total organic carbon (TOC) with a Shimadzu ASI5000-A auto sampler instrument. The total phenol concentration was determined using the colorimetric 4-aminoantipyrine method. ${ }^{20}$ Phenolic compounds react with 4aminoantipyrine at $\mathrm{pH} \mathrm{7.9(1)}$ in the presence of potassium ferricyanide to form a colored compound of antipyrine, which is photometric measured at $\lambda=500 \mathrm{~nm}$. Data were recorded on a UV-1800p UV-visible Shimadzu spectrophotometer. Dissolved iron was determined by inductively coupled plasma mass spectroscopy (ICP-MS) on an Optima 7300 DV Perkin-Elmer spectrometer. Hydrogen peroxide was spectrophotometrically analyzed at $450 \mathrm{~nm}$ by the red-orange peroxovanadium ion, $\mathrm{VO}\left(\mathrm{O}_{2}\right)^{2+}$, generated upon reaction with ammonium metavanadate in acidic solution. ${ }^{21}$ Finally, the reaction intermediate products were analyzed with a HPLC-MS TSQ Quantum Access Max Thermo Electron device. Samples were prepared in 3:2 methanol/water mixtures with $5 \%$ ammonia ( $\mathrm{pH} 10.0)$.

The recyclability of the catalyst was studied by filtering the catalyst after the photocatalytic tests. After drying, the catalyst was used in a second cycle.

\section{RESULTS AND DISCUSSION}

3.1. Characterization of the Catalyst. X-ray powder diffraction pattern of the as-synthesized catalyst is displayed in Figure 1 (top). The powder pattern fully agrees with that calculated from the reported single crystal study. ${ }^{15}$ The evolution of the particle size during milling was observed by SEM. Figure 2a shows two representative micrographs of assynthesized FeHPAA at different magnifications. As it can be seen, the as-synthesized solid has variable (large) particle sizes ranging 15 to $30 \mu \mathrm{m}$. In order to gain deeper insight into the surface characteristics of the catalyst, samples were ground during different vibratory milling times and their photocatalytic behaviors were compared to the sample reference, see below. Figure $2 \mathrm{~b}$ shows representative SEM micrographs of the catalysts after $4 \mathrm{~h}$ of milling. These images reveal that the use of 


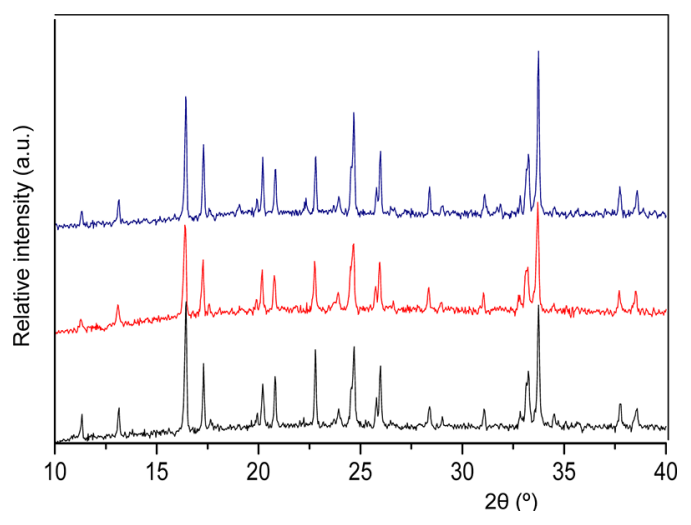

Figure 1. X-ray powder diffraction patterns for FeHPAA: (top) assynthesized hybrid, (intermediate) after vibratory milling for $4 \mathrm{~h}$, and (bottom) as-synthesized catalyst after a photocatalytic test. Constant offset values (vertically) have been added to the first two patterns for better visualization.
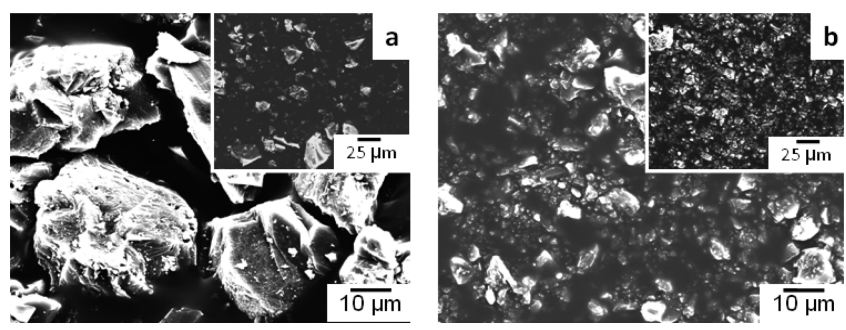

Figure 2. Selected SEM images for FeHPAA: (a) as-synthesized and (b) after $4 \mathrm{~h}$ of milling.

$4 \mathrm{~h}$ of vibratory milling significantly reduced the average size of the particles to lower than $10 \mu \mathrm{m}$. The milling does not affect to the crystal structure as shown in Figure 1 (intermediate) but increases considerably the surface area, from 0.8 to $16.9 \mathrm{~m}^{2} / \mathrm{g}$ after $4 \mathrm{~h}$ of milling. Since smaller particle sizes are related to larger surface areas, it was hypothesized that the milled powders may have larger photocatalytic activities than the unmilled one.

Figure 3 displays the UV-vis spectrum for as-synthesized FeHPAA. Additionally, the spectra for the sample milled for $4 \mathrm{~h}$ and the solid recovered after a phenol photodegradation

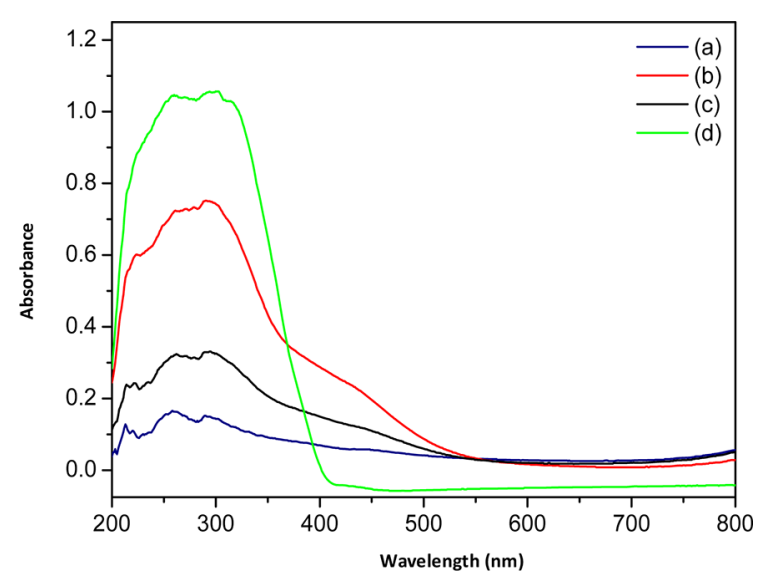

Figure 3. UV-vis spectra for $150 \mathrm{mg}$ of the catalysts, mixed with 350 $\mathrm{mg}$ of $\mathrm{BaSO}_{4}$ : (a) as-synthesized FeHPAA, (b) catalyst after $4 \mathrm{~h}$ of vibratory milling of as-synthesized FeHPAA, (c) as-synthesized FeHPAA catalyst after a photocatalytic test, and (d) $\mathrm{TiO}_{2}$ (DegussaP25). reaction are also given. Furthermore, the spectrum of the standard $\mathrm{TiO}_{2}$ catalyst (Degussa-P25) is also displayed. The spectrum for as-synthesized FeHPAA displays the characteristic absorptions corresponding to ligand to metal charge-transfer and iron electronic transitions. ${ }^{22}$ Interestingly, the spectra of the milled and used FeHPAA photocatalysts exhibit a substantial widening of the absorbance at the used UVA wavelength region, as compared with the $\mathrm{TiO}_{2}$ spectrum that remains invariable, as expected. As shown below, these changes in absorbance result in a more efficient photocatalytic activity.

Figure 4 displays the zeta potential vs $\mathrm{pH}$ values of the asprepared FeHPAA hybrid aqueous suspension. This initial

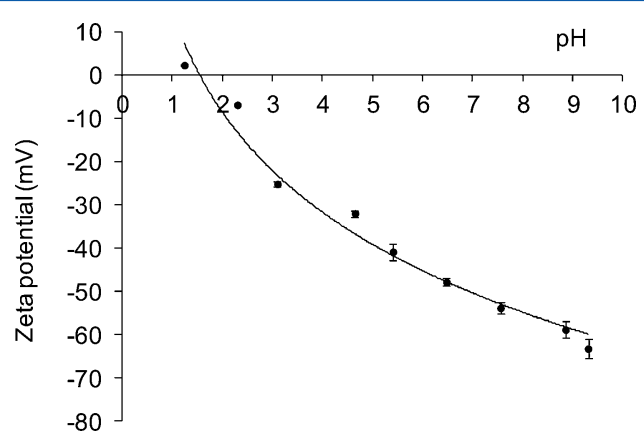

Figure 4. Zeta potential vs $\mathrm{pH}$ of as-prepared FeHPAA hybrid in aqueous suspension.

characterization was carried out to determine if dispersion problems are likely to take place for some $\mathrm{pH}$ values. The isoelectric point (IEP) of the catalyst suspension was just below 2.0. Within the $\mathrm{pH}$ range varying from 3.5 to 5.5 , the zeta potential of the catalyst roughly decreases from -29 to -41 $\mathrm{mV}$, respectively (Figure 4). These zeta potential values are large enough to maintain the particles dispersed. However, if the generation of acidity upon reaction (see below) is large, additives or external $\mathrm{pH}$ control would be required as the catalyst suspension become progressively unstable below a $\mathrm{pH}$ value of 3.0.

3.2. Photocatalytic Measurements. The stability of the hydroxyphosphonoacetatic ligand, HPAA, in solution as well as within the catalyst was first checked by irradiation with UVA light in the presence of $\mathrm{H}_{2} \mathrm{O}_{2}$. Note that phenol was not added in this first test. As can be seen in Figure 5, the ligand does not

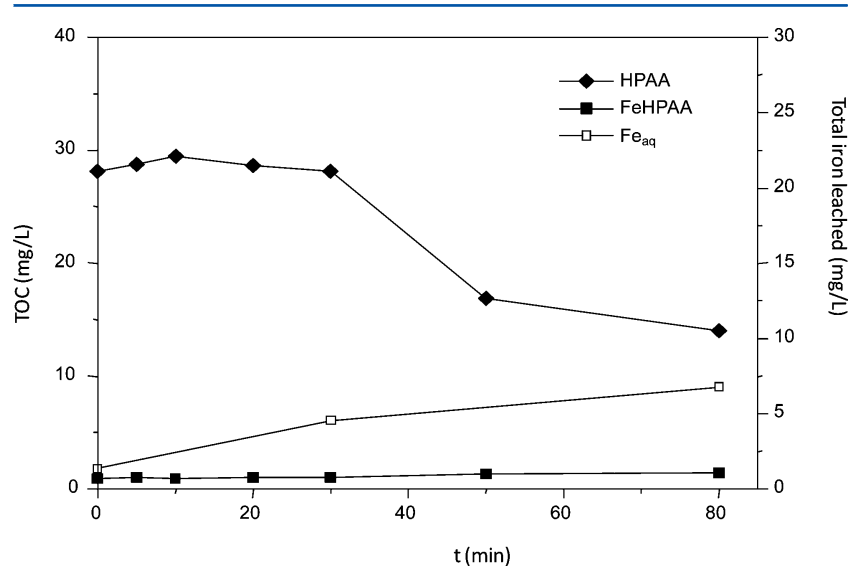

Figure 5. Stability of the ligand and the catalyst under UVA radiation (solid symbols, left scale axis). The total iron leached from the catalyst is also plotted (open symbols, right scale axis). 
mineralize during the first $30 \mathrm{~min}$, and then mineralization starts to take place. At 80 min of irradiation, about $50 \%$ of the initial ligand is mineralized. However, when forming part of the catalyst, mineralization was not detected during the whole exposing time to UVA irradiation. As it will be shown below, the initial $\mathrm{pH}$ values are important and so we report the value for the suspension containing the as-prepared FeHPAA solid and $\mathrm{H}_{2} \mathrm{O}_{2}$, which was very close to 4.5. In addition, iron leaching from the catalyst is known to be a very important parameter as it will influence the photocatalysis through a homogeneous mechanism. ${ }^{23,24}$ Thus, Figure 5 also displays the total iron leached to the solution determined as described in the Experimental Section. For the catalyst irradiated with UVA in the presence of $\mathrm{H}_{2} \mathrm{O}_{2}$, up to $7 \mathrm{ppm}$ of iron was lixiviated after 80 min.

A preliminary photocatalytic study on the degradation and mineralization of phenol $(50 \mathrm{mg} / \mathrm{L})$ was undertaken. It should be noted that the addition of $\mathrm{H}_{2} \mathrm{O}_{2}$, final concentration of 250 $\mathrm{mg} / \mathrm{L}$, was that required for full stoichiometric mineralization of phenol to produce $\mathrm{CO}_{2}$ and $\mathrm{H}_{2} \mathrm{O}$. The initial $\mathrm{pH}$ value was not adjusted, $\mathrm{pH}_{0} 4.0$, and the catalyst concentration was 220 $\mathrm{mg} / \mathrm{L}$. Figure 6 displays the phenol degradation and total

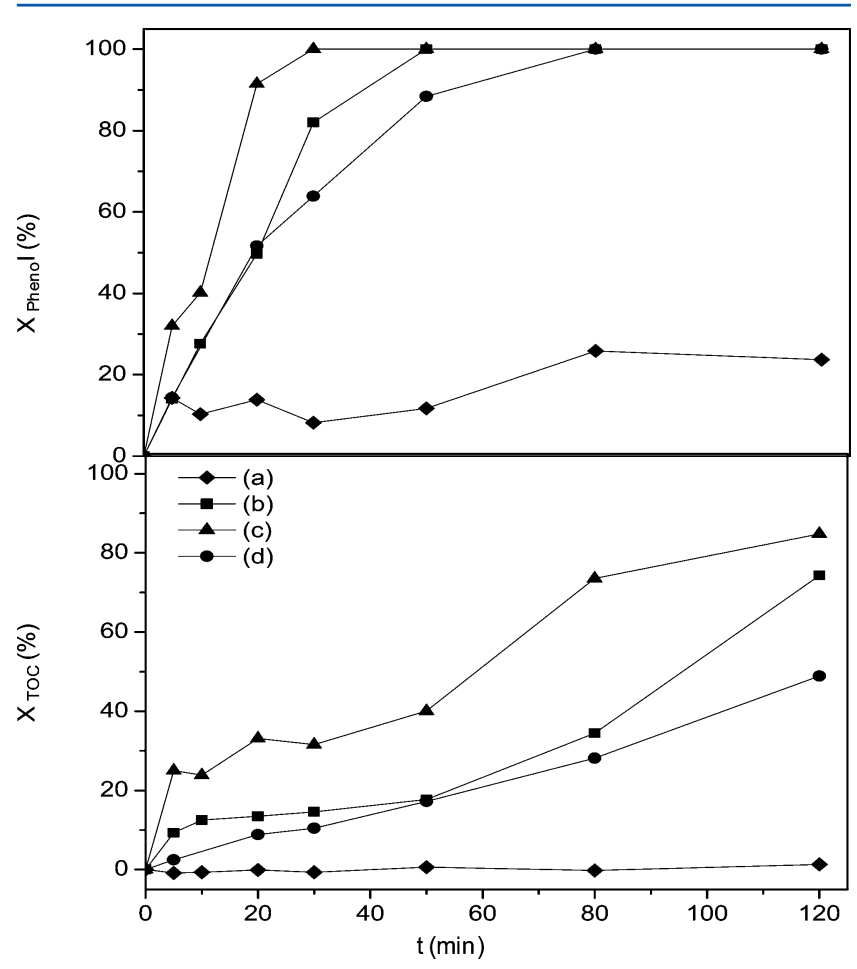

Figure 6. Time evolution of phenol (top) and TOC (bottom) conversions under UVA irradiation: (a) without catalyst, (b) with asprepared FeHPAA catalyst, (c) with as-prepared FeHPAA catalyst previously activated by UVA irradiation for $30 \mathrm{~min}$, and (d) with standard $\mathrm{TiO}_{2}$ catalyst (Degussa-P25) under exactly the same conditions.

mineralization under these conditions. As expected, see Figure $6 \mathrm{a}$, in the absence of the hybrid catalyst, phenol underwent little degradation and mineralization does not take place within 120 min of reaction. Hydrogen peroxide is a moderate oxidant but it is known to be ineffective for certain refractory organic pollutants. ${ }^{25,26}$ However, when the as-prepared catalyst was present, phenol has fully reacted in $50 \mathrm{~min}$ and TOC removal was increased with about $30 \%$ of TOC being removed after 80 min, see Figure $6 \mathrm{~b}$. The efficiency was further improved when the catalyst was subjected to a pretreatment with UVA radiation and $50 \mathrm{mg} \mathrm{L}^{-1}$ of $\mathrm{H}_{2} \mathrm{O}_{2}$ for $30 \mathrm{~min}$, in the absence of phenol $\left(\mathrm{pH}_{0} 4.0\right)$. After pretreatment, the photocatalytic test indicated that the TOC removal reached to $75 \%$ at $80 \mathrm{~min}$ of irradiation, see Figure $6 c$. Catalyst pretreatment has been reported to be effective to improve the photocatalytic conversion rate(s). ${ }^{27,28}$ Figure $6 \mathrm{~d}$ shows the phenol and TOC conversion for a wellknown $\mathrm{TiO}_{2}$ catalyst (P25 from Degussa) for the sake of comparison. It can be seen that under the studied conditions, FeHPAA displays a much higher photocatalytic activity than $\mathrm{TiO}_{2}-\mathrm{P} 25$ at any reaction time. Finally, the bulk structure of FeHPAA after the phenol mineralization does not change as the powder pattern of the solid collected after the catalytic test is identical to that of the initial solid, see bottom pattern in Figure 1.

Phenol disappearance from solution was relatively fast, 50 and $30 \mathrm{~min}$ for the raw and preactivated catalysts, respectively. This confirms previous reports ${ }^{29,30}$ that have established a general pattern of degradation for this molecule. Intermediates are formed within the first minutes at the same time as phenol is degraded, the main reactions being aromatic ring oxidation (hydroquinone, catechol) and ring cleavage compounds (f.i. muconic acid). Finally, low carbon content carboxylic acids are formed at the end of the photocatalytic reaction. In this work, catechol and hydroquinone were found as main intermediates from phenol photodegradation at $30 \mathrm{~min}$ of reaction, whereas methaphosphoric and orthophosphoric acids appeared in solution as byproducts of partial photodegradation of the ligand HPAA, see Table 1.

Table 1. Reaction Intermediates Formed during the Photodegradation of Phenol Determined by HPLC

\begin{tabular}{clcc}
$\begin{array}{c}\text { mass fraction } \\
(\mathrm{m} / \mathrm{z})\end{array}$ & \multicolumn{1}{c}{ compound } & $\begin{array}{c}\text { initial time } \\
(\mathrm{min})\end{array}$ & final time $(\mathrm{min})$ \\
79.08 & $\begin{array}{c}\text { metaphosphonic } \\
\text { acid }\end{array}$ & 0 & $\begin{array}{c}\text { increases with } \\
\text { time }\end{array}$ \\
93.09 & $\begin{array}{l}\text { phenol } \\
\text { orthophosphonic } \\
\text { acid }\end{array}$ & 0 & 30 \\
109 & catechol & 0 & $\begin{array}{c}\text { increases with } \\
\text { time }\end{array}$ \\
$125-126$ & hydroquinone & 5 & 30 \\
& & 5 & 30
\end{tabular}

Decreasing $\mathrm{H}_{2} \mathrm{O}_{2}$ concentration below the stoichiometric value, $250 \mathrm{mg} / \mathrm{L}$, (study not shown) strongly diminished the efficiency of phenol mineralization. Hence, stoichiometric $\mathrm{H}_{2} \mathrm{O}_{2}$ concentration was used for all experiments described hereafter.

In order to establish the optimum catalyst concentration, phenol photodegradation and mineralization were studied with three different loads of the catalyst using the preactivated catalyst at initial $\mathrm{pH}$ of 4.0. Figure 7 shows larger conversions for higher loadings of the catalyst in both the phenol degradation and TOC removal suggesting that the reaction rate is related to the amount of sites of iron exposed to light radiation. For a catalyst loading of $700 \mathrm{mg} / \mathrm{L}$, phenol disappeared from solution in $5 \mathrm{~min}$ and $90 \%$ of mineralization was attained at $80 \mathrm{~min}$. The recyclability of the catalyst has been also studied by filtering the catalyst after the $700 \mathrm{mg} / \mathrm{L}$ test. Only, slightly above $650 \mathrm{mg}$ was recovered, so a second test with $500 \mathrm{mg} / \mathrm{L}$ of used-catalyst was carried out; see Figure $7 \mathrm{~d}$. It can be seen that the photocatalytic activity of FeHPAA in this second test is higher than in the first one, pointing out that the changes on the catalyst surface during the first reaction 


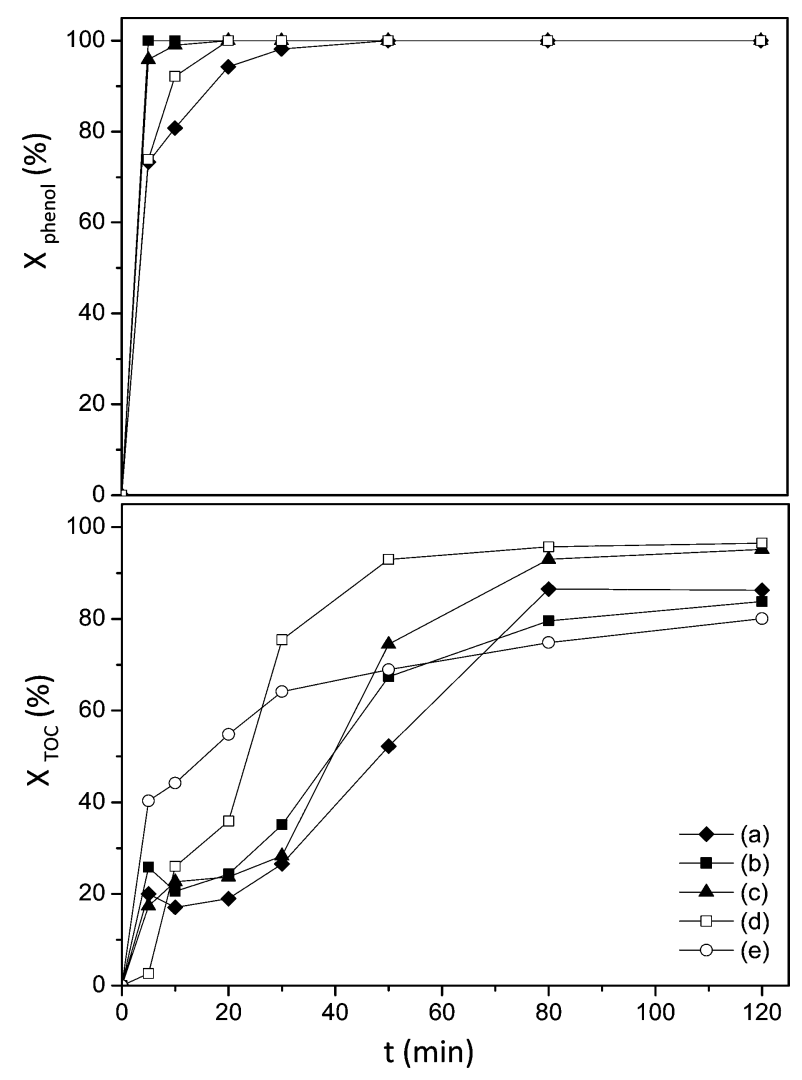

Figure 7. Time evolution of phenol (top) and TOC (bottom) conversions under different contents of as-synthesized FeHPAA catalyst: (a) 220, (b) 500, and (c) $700 \mathrm{mg} / \mathrm{L}$. Results for two additional tests are reported (d) a second-cycle test with $500 \mathrm{mg} / \mathrm{L}$, open squares and (e) a test in homogeneous conditions, $3 \mathrm{ppm}$ of $\mathrm{Fe}$ (open circles).

cycle, related to the concentration of the exposed iron and its coordination environment, help the performances in the second cycle.

The time-dependent $\mathrm{pH}$ values for the photocatalytic tests described just above are displayed in Figure 8 (top). The initial $\mathrm{pH}$ values ranged between 3.9 and 4.3 depending upon the amount of catalyst. In any case, a pronounced drop of $\mathrm{pH}$ values takes place up to approximately $30 \mathrm{~min}$. The minimum $\mathrm{pH}$ value was close to 3.3. This drop has been observed before $^{25}$ and it is very likely joined to the production of acidic intermediate species for phenol degradation. This behavior agrees with the observed intermediates which were given in Table 1. Figure 8 (bottom) gives the total iron leached to the solution; the pretreatment leads to the existence of iron in the solution right from the beginning of the photocatalytic tests. Under the tested conditions, the maximum concentration of leached-iron is reached at $80 \mathrm{~min}$. The evolution of lixiviated iron is quite different from that observed in the absence of phenol, see Figure 5. The time evolution pattern of lixiviated iron has a volcano shape which has been already reported. ${ }^{31,32}$ This behavior was attributed to an initial leaching with a subsequent readsorption process. It is important to highlight that this evolution nicely matches that of $\mathrm{pH}$. As $\mathrm{pH}$ drops iron leaching is favored but when $\mathrm{pH}$ increases, the readsorption takes place and lower amounts of total dissolved iron is present in the reaction medium. It must be noted that there is iron leaching at the start of the experiment due to the pretreatment.

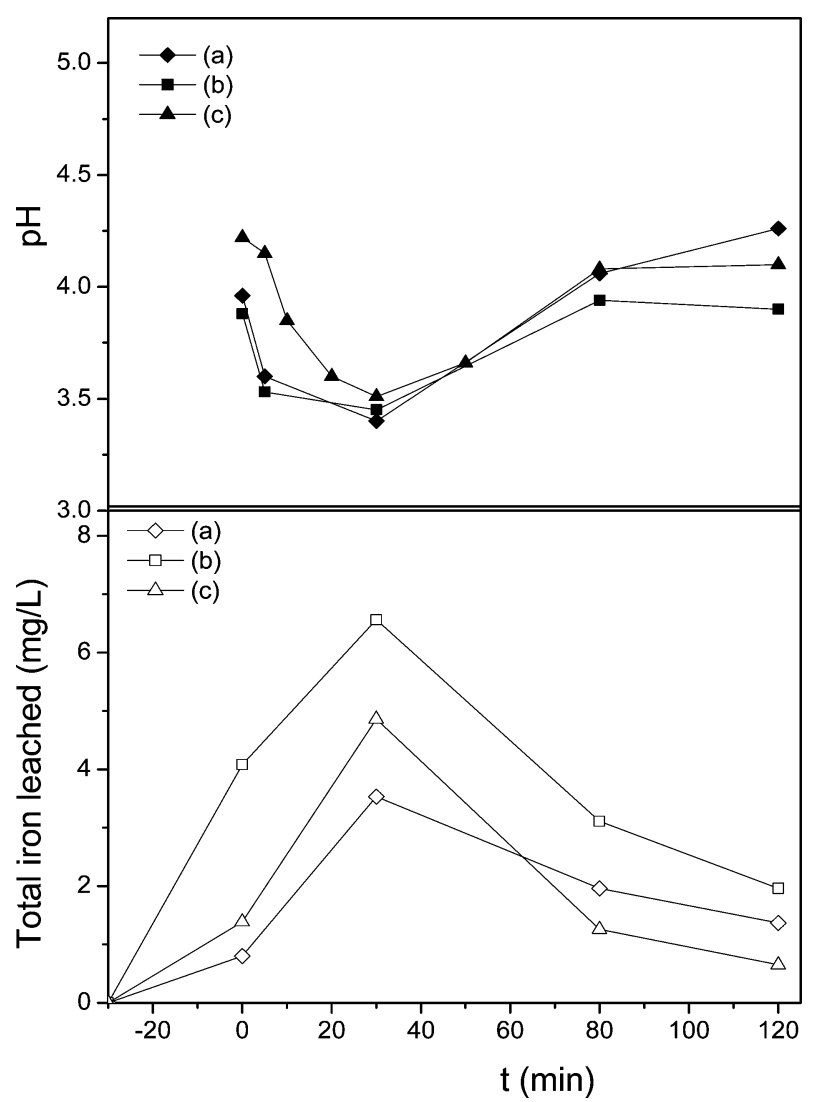

Figure 8. Time evolution of (top) $\mathrm{pH}$ and (bottom) total iron leached, for the photocatalytic reactions with different contents of assynthesized FeHPAA catalyst: (a) 220, (b) 500, and (c) $700 \mathrm{mg} / \mathrm{L}$.

The amount of dissolved iron is very important as it also contributes to the overall photocatalytic reaction through a homogeneous photocatalytic mechanism. Taking it all together, FeHPAA photocatalyst should be considered as a complex liquid-solid mixed phase photocatalyst rather than a simple heterogeneous photocatalyst. Rather than a detrimental effect, sustained slow delivery of iron upon reaction could be considered as an advantage in advanced photocatalytic processes. In order to assess the homogeneous catalytic contribution, a phenol photodegradation experiment was conducted with the solution of a previous experiment (500 $\mathrm{mg} / \mathrm{L}$ of as-synthesized FeHPAA) but filtered off, i.e., using the leached iron which was very close to $3 \mathrm{ppm}$ and the initial $\mathrm{pH}$ value was 3.8. Under these homogeneous catalysis conditions, see Figure $7 \mathrm{e}$, the mineralization was higher at short reaction times, before $30 \mathrm{~min}$, but smaller at longer reaction times, i.e., about $80 \%$ after $120 \mathrm{~min}$. This homogeneous catalysis contribution to the overall phenol photo-oxidation may be responsible for an enhanced mineralization of phenol compare to the standard $\mathrm{TiO}_{2}$ catalyst, where the photocatalytic process only takes place on the surface of the semiconductor particles.

The role of the initial $\mathrm{pH}$ value on the photocatalytic performances of FeHPAA has also been investigated. Figure 9 displays the TOC conversion curves for $700 \mathrm{mg} / \mathrm{L}$ of assynthesized FeHPAA at different initial $\mathrm{pH}$ values. As it can be seen, for the initial $\mathrm{pH}$ value of 3.5 , the conversion is slightly higher at early ages (before $30 \mathrm{~min}$ ) but slightly lower at later ages. For $\mathrm{pH}$ values of 4.0 and higher, the conversions are quite similar (see Figure 9). Figure 10 displays the $\mathrm{pH}$ evolution and the amount of lixiviated iron for different initial $\mathrm{pH}$ values. 


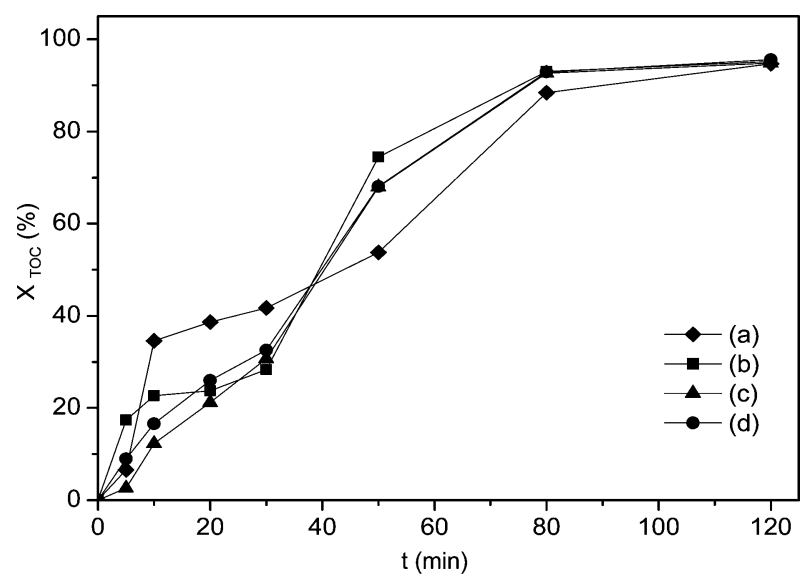

Figure 9. Time evolution of the TOC conversion at different initial $\mathrm{pH}$ values: $\mathrm{pH}_{0}$ 3.5(a), 4.0 (b), $5.0(\mathrm{c})$, and $6.0(\mathrm{~d})$.

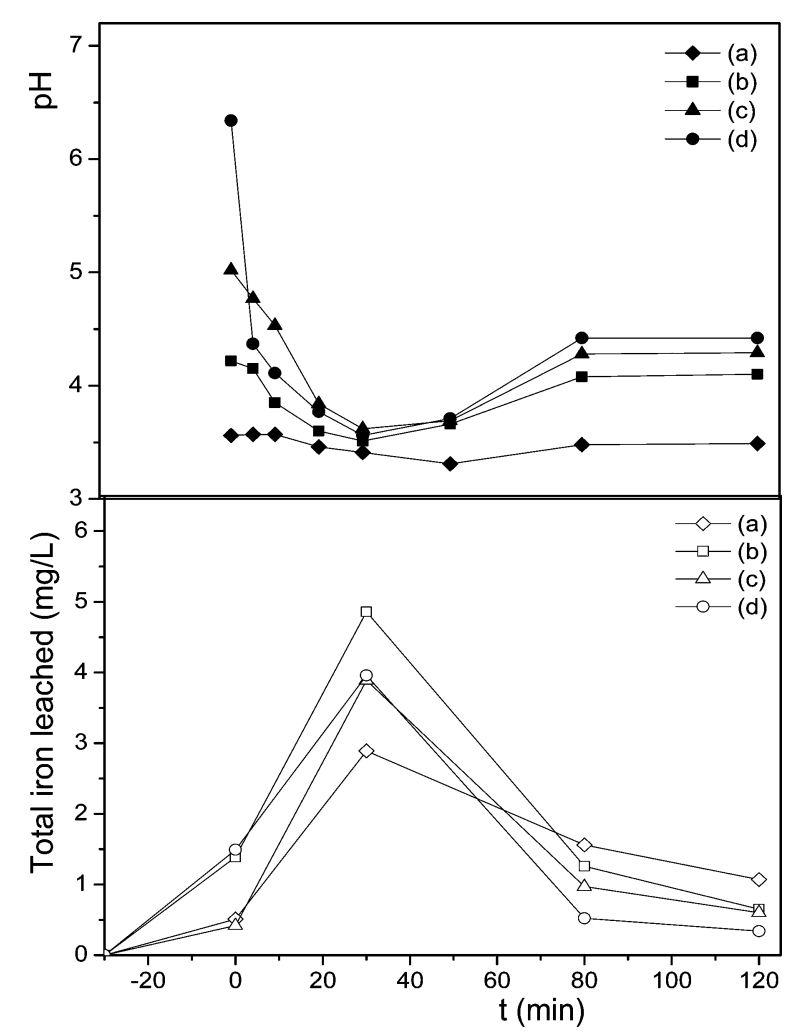

Figure 10. Time evolution of (top) $\mathrm{pH}$ and (bottom) total iron leached at different initial $\mathrm{pH}$ values: $\mathrm{pH}_{0} 3.5$ (a), 4.0 (b), 5.0 (c), and 6.0 (d).

Leached iron follows a volcano pattern as already shown in Figure 8, which correlates with the $\mathrm{pH}$ variation along the photocatalytic tests.

The effect of decreasing the particle size, by milling, on the photocatalytic properties of FeHPAA is shown in Figure 11 where TOC conversion values are compared to those obtained for as-synthesized FeHPAA. It must be noticed that this experiment was carried out without $\mathrm{pH}$ modification, $\mathrm{pH}_{0} 4.3$, and so without counteranion. In this case, TOC conversion at 120 min reached $100 \%$ for as-synthesized FeHPAA. It can be seen that sample milled for $4 \mathrm{~h}$ showed the best results for phenol photodegradation in the first $50 \mathrm{~min}$ with a TOC conversion above $85 \%$. Figure 11 also displays the hydrogen peroxide consumptions for the tests using the two FeHPAA

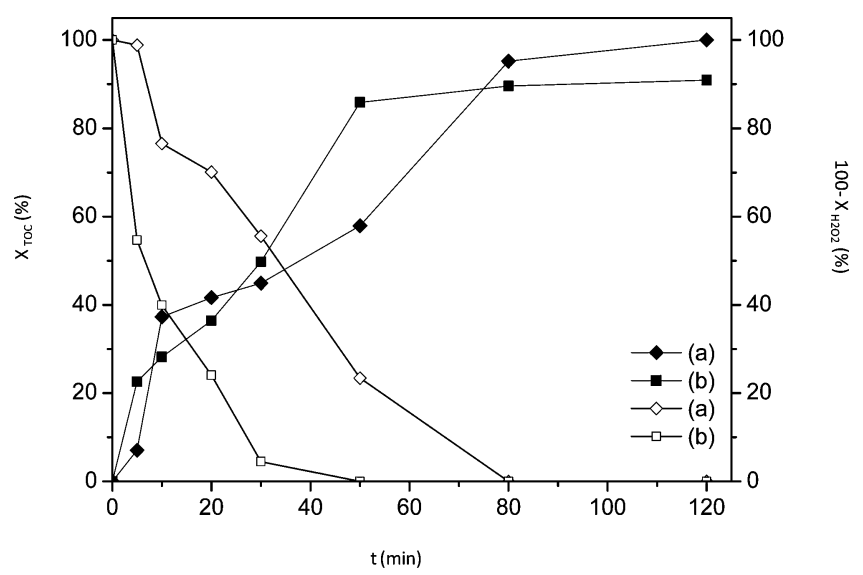

Figure 11. Time evolution of the TOC conversion (full symbols, right scale axis) and hydrogen peroxide reverse conversion (open symbols, left scale axis) for two different treatments of the catalyst, $700 \mathrm{mg} / \mathrm{L}$ : (a) as-synthesized and (b) $4 \mathrm{~h}$ of vibratory milling.

samples. The smaller particle size of milled FeHPAA results in higher reactivity and therefore, the peroxide concentration drops quite abruptly with no measurable content for reaction times of 50 min or longer. In addition, the $\mathrm{H}_{2} \mathrm{O}_{2}$ content at 50 min for as-synthesized FeHPAA is still about $20 \%$. It is also important to note that total leached iron for the milled catalyst is much larger than those of the remaining studied samples. The measured values are as high as $10 \mathrm{ppm}$. It is reasonable to assume that increased rates of iron leaching by milling are responsible for a rapid consumption of $\mathrm{H}_{2} \mathrm{O}_{2}$, through, for instance, Fenton reactions occurring in solution. This, in turn, slows the photocatalytic process at longer times of reaction. Thus, the highest TOC conversion, $100 \%$ at $120 \mathrm{~min}$, was reached with the as-synthesized FeHPAA, for which a more sustained $\mathrm{H}_{2} \mathrm{O}_{2}$ consumption with time occurred. We speculate that $\mathrm{Fe}(\mathrm{II}) / \mathrm{Fe}$ (III) cycling in solution would play, therefore, a major role to accomplish phenol mineralization. In addition, fast dissolution of iron from the milled catalyst upon reaction is not compensated by partial readsorption of the leached iron and so, iron concentration in solution does not decrease at high reaction times. Figure 12 shows the $\mathrm{pH}$ evolution and the total leached iron content for these two types of samples. As discussed above, $\mathrm{pH}$ decreases at the beginning of the photocatalytic degradation of phenol very likely due to the formation of acidic intermediate species, including iron complexes, in solution. For reaction times longer than 40 min, $\mathrm{pH}$ values start to increase, just when the iron uptake on the catalyst surface is likely taking place.

3.3. XPS Measurements. XPS experiments were performed to study the oxidation state of iron at the surface of the catalyst and the interactions between metal ions and the ligand 2-hydroxyphosphonoacetate. ${ }^{33-35}$ XPS data for FeHPAA before and after pretreatment (data given in the Supporting Information, Figures S1 and S3) indicate the existence of significant changes in surface composition of the catalyst after pretreatment, with the relative atomic ratios of $\mathrm{Fe}$ and $\mathrm{O}$ increasing at the expense of that of $\mathrm{C}$. Remarkably, pretreatment increased almost 2-fold the iron concentration on the catalyst surface, although the ratio $\mathrm{Fe}(\mathrm{II}) / \mathrm{Fe}$ (III) was roughly maintained, i.e., 60/40. Partial removal of carbonaceous matter from the catalyst surface, together with the appearance of phosphate ions during phenol photodegradation point to a photolytic process is occurring on the catalyst surface. This 


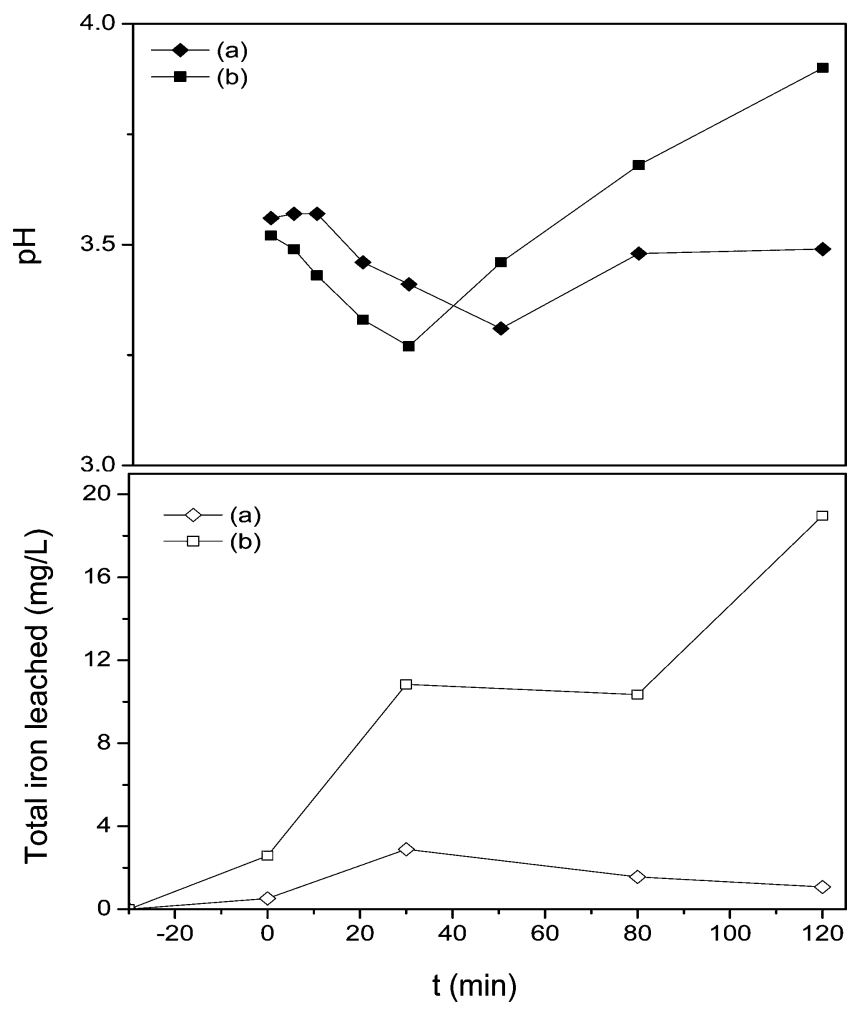

Figure 12. Time evolution of (top) $\mathrm{pH}$ and (bottom) total iron leached for different treatments of the catalyst: (a) as synthesized and (b) after $4 \mathrm{~h}$ of vibratory milling.

photolytic process would eventually lead the formation of charged iron species, probably $\mathrm{Fe}$ (III) carboxylates, acting as initiators of the photocatalytic reaction and a main source of iron in solution, through a photo-Fenton process. ${ }^{32}$ Furthermore, it is well-known that aqueous hydrogen peroxide decomposes over heterogeneous catalysts with the formation of strong oxidants, including hydroxyl radicals, that oxidize organic molecules on iron-containing surfaces. ${ }^{31,32}$ So, UVA preactivation has a double role: (i) increases the surface iron concentration and (ii) generates photoactive iron species by leaching at the start of the photocatalytic reaction. Both modifications help to increase the photodegradation of phenol at early reaction times. Nevertheless, the photolytic processes also entail changes in the nature of the photoactive iron species on the catalyst surface that may alter the inertia of the catalyst in subsequent photocatalytic cycles. Thus, a slight initial delay in phenol mineralization was observed in a second photocatalytic cycle (Figure 7).

Figure 13 shows the XPS raw spectra for the O1s region corresponding to three selected samples. The deconvoluted curves are deposited as Supporting Information. To a first approximation, they consist of two components. The main peak located at $531.3-531.4 \mathrm{eV}$ is mostly attributed to $\mathrm{Fe}-\mathrm{O}-\mathrm{P}$ and $\mathrm{Fe}-\mathrm{O}-\mathrm{H}$ type-oxygen and possibly strongly adsorbed water. The shoulder at 532.8-533.1 eV may be assigned to oxygens belonging to both phosphonic, $\mathrm{POH}$, and carboxylic, $\mathrm{CO}_{2} \mathrm{H}$, groups. $^{36}$ After photoreaction, Figure $13 \mathrm{c}$, the area of this second component markedly decreases at the expense of the main peak, probably due to an increased presence of $\mathrm{Fe}-\mathrm{OH}$ bonds on the catalyst surface. It is also remarkable the practical absence of segregated iron oxide in the studied catalysts. Iron oxide is characterized by a peak with a binding energy located at

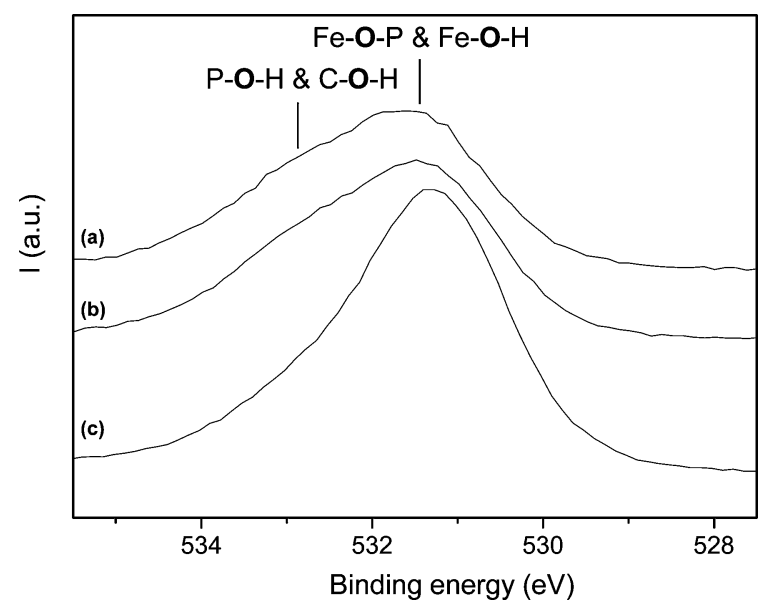

Figure 13. XPS O1s raw data: (a) as-synthesized, (b) after milling for $4 \mathrm{~h}$, and (c) as-synthesized after a photocatalytic test. The two main bands are labeled.

$530 \mathrm{eV}$ and corresponding to the bridging $\mathrm{O}^{2-}$ ion, $\mathrm{Fe}-\mathrm{O}-\mathrm{Fe}$. This is consistent with high phenol photodegradation rates exhibited by the catalysts, because iron is not set aside into inactive oxide forms. Finally, Figure 14 shows the XPS spectra

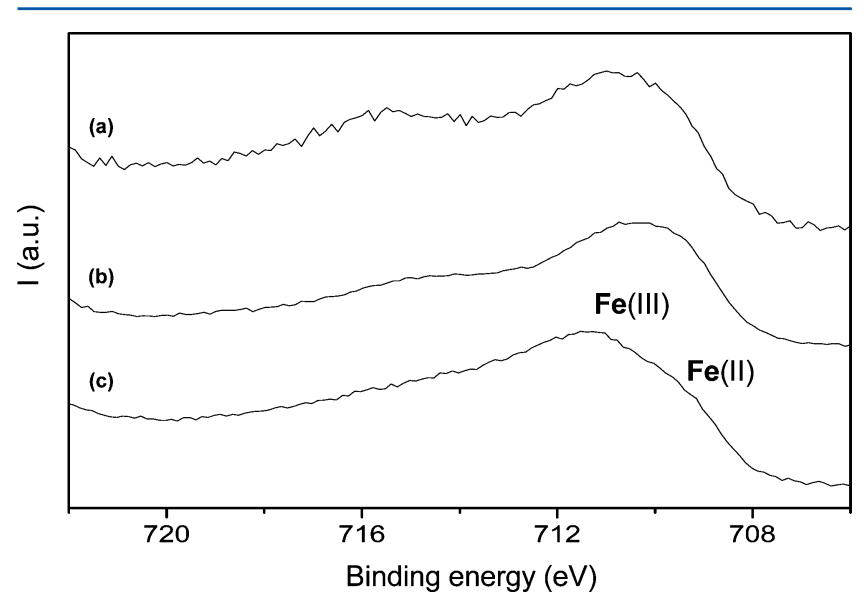

Figure 14. XPS Fe 2p3/2 raw data: (a) as-synthesized, (b) after milling for $4 \mathrm{~h}$, and (c) as-synthesized after a photocatalytic test.

for the $\mathrm{Fe} 2 \mathrm{p} 3 / 2$ region corresponding to three representative samples. The key finding is the higher $\mathrm{Fe}(\mathrm{II}) / \mathrm{Fe}$ (III) ratio found in the used catalyst after photoreaction; see Figure 14c and the Supporting Information for the analysis of the data. ${ }^{36,37}$ This measurement supports the idea that iron is readsorbed on the catalyst surface as $\mathrm{Fe}$ (II) species. This assumption is further confirmed by the fact that this process just starts at low $\mathrm{H}_{2} \mathrm{O}_{2}$ concentrations, i.e., at times latter than approximately $50 \mathrm{~min}$. In addition, the increased concentration of iron on surface of the used catalyst has a beneficial effect in a second cycle of phenol mineralization (see Figure 7).

\section{CONCLUSIONS}

$\mathrm{Fe}\left[\mathrm{HO}_{3} \mathrm{PCH}(\mathrm{OH}) \mathrm{COO}\right] \cdot 2 \mathrm{H}_{2} \mathrm{O}$ is an efficient Fenton photocatalyst for phenol oxidation under UVA radiation. The stability of the catalyst under the studied conditions is quite high, and it leaches a very small amount of Fe species, $\sim 4 \mathrm{ppm}$, which is advantageous as the mixed heterogeneous-homogeneous catalytic processes result in very high phenol mineralization. 
The leaching from the catalyst, and subsequent partial iron readsorption, is linked to the $\mathrm{pH}$ evolution of the reaction medium. The $\mathrm{pH}$ variation along the phenol photoreaction has been measured and it initially decreases likely joined to the formation of acidic intermediates. Later, slightly increases when these intermediates are fully mineralized. In addition, milling decreases the particle size of the catalyst and so increases the phenol mineralization rates at early reaction times. However, the rapid hydrogen peroxide reaction decreases the mineralization at later ages. Analysis by X-ray photoelectron spectroscopy revealed important chemical modifications occurring on the surface of the catalyst after preactivation under UVA without phenol, and also after phenol photodegradation. These modifications increase the availability of $\mathrm{Fe}(\mathrm{II})$ species at the surfaces of the catalyst which increases the phenol mineralization conversion. A mineralization degree as high as $90 \%$ was found for reaction times of $80 \mathrm{~min}$ under optimized conditions.

\section{ASSOCIATED CONTENT}

\section{S Supporting Information}

Deconvoluted XPS O1s data for as-synthesized FeHPAA (Figure S1a), pretreated FeHPAA (Figure S2a), ball-milled FeHPAA for $4 \mathrm{~h}$ (Figure S3a), and as-synthesized FeHPAA after a photocatalytic test (Figure S3a). The analytical results are given in the insets of the graphics. Deconvoluted XPS Fe $2 \mathrm{p}^{3 / 2}$ data for the same materials are given in Figures $\mathrm{S} 1 \mathrm{~b}-\mathrm{S} 4 \mathrm{~b}$. This material is available free of charge via the Internet at http://pubs.acs.org.

\section{AUTHOR INFORMATION}

\section{Corresponding Author}

*E-mail: g_aranda@uma.es.

\section{Notes}

The authors declare no competing financial interest.

\section{ACKNOWLEDGMENTS}

This work is funded by MAT2010-15175 research grant which is cofunded by FEDER. I.S. thanks a Ramón y Cajal fellowship (RYC-2008-03523).

\section{REFERENCES}

(1) Zhou, H. C.; Long, J. R.; Yaghi, O. M. Chem. Rev. 2012, 112, 673-674.

(2) Llabrés i Xamena, F. X.; Corma, A.; García, H. J. Phys. Chem. C 2007, 111, 80-85.

(3) Clearfield, A.; Demadis, K. D. Metal phosphonate Chemistry: from synthesis to applications; RSC-Publishing: Cambridge, U.K., 2012.

(4) Choi, J.-R.; Tachikawa, T.; Fujitsuka, M.; Majima, T. Langmuir 2010, 26 (13), 10437-10443.

(5) Kataoka, Y.; Sato, K.; Miyazaki, Y.; Masuda, K.; Tanaka, H.; Naito, S.; Mori, W. Energy Environ. Sci. 2009, 2, 397-400.

(6) Clearfield, A. Prog. Inorg. Chem. 1998, 47, 371-510.

(7) Garnon, K. J.; Perry, H. P.; Clearfield, A. Chem. Rev. 2012, 112, 1034-1054.

(8) Esplugas, S.; Giménez, J.; Contreras, S.; Pascual, E.; Rodríguez, M. Water Res. 2002, 36, 1034-1042.

(9) Oller, I.; Malato, S.; Sánchez-Pérez, J. A. Sci. Total Environ. 2011, 409, 4141-4166.

(10) Herney-Ramirez, J.; Vicente, M. A.; Madeira, L. M. Appl. Catal., B 2010, 98, 10-26.

(11) Zapata, A.; Velegraki, T.; Sánchez-Pérez, J. A.; Mantzavinos, D.; Maldonado, M. I.; Malato, S. Appl. Catal., B 2009, 88, 448-454.

(12) Kim, K. H.; Ihn, S. K. J. Hazard. Mater. 2011, 186, 16-34.
(13) Han, Z.; Dong, Y.; Dong, S. J. Hazard. Mater. 2011, 189, 241248.

(14) Ma, T. Y.; Lin, X. Z.; Yuan, Z. Y. J. Mater. Chem. 2010, 20, $7406-7415$.

(15) Fu, R.; Xiang, S.; Zhang., H.; Zhang., J.; Wu., X. Cryst. Growth Des. 2005, 5, 1795-1799.

(16) Colodrero, R. M. P.; Olivera-Pastor, P.; Cabeza, A.; Papadaki, M.; Demadis, K. D.; Aranda, M. A. G. Inorg. Chem. 2010, 49, 761-768.

(17) Salinaro, A.; Serpone, N. Pure Appl. Chem. 1999, 71, 303-320.

(18) Salinaro, A.; Emeline, A. V.; Zhao, J.; Hidaka, H. Pure Appl. Chem. 1999, 71, 321-335.

(19) Natoli, A.; Cabeza, A.; De La Torre, A. G.; Aranda, M. A. G.; Santacruz, I. J. Am. Ceram. Soc. 2012, 95, 502-508.

(20) Rice, E. W.; Baird, R. B.; Eaton, A. D.; Clesceri, L. S. Standard Methods for the Examination of Water and Wastewater; American Water Works Association/American Public Works Association/Water Environment Federation: New York, 1998.

(21) Nogueira, R. F. P.; Oliveira, M. C.; Paterlini, W. C. Talanta 2005, 66, 86-91.

(22) Lever, A. B. P. Inorganic Electronic Spectroscopy, 2nd ed.; Elsevier Science: Amsterdam, 1984.

(23) Kavitha, V.; Palanivelu, K. Chemosphere 2004, 55, 1235-1243.

(24) Ramirez, J. H.; Duarte, F. M.; Martins, M. F. G.; Costa, C. A.; Madeira, L. M. J. Chem. Eng. J. 2009, 148, 394-404.

(25) Bishop, D. F.; Stern, G.; Fleischman, M.; Marshall, L. S. Ind. Eng. Chem. Process Des. Dev. 1968, 7, 110-117.

(26) Kitis, M.; Kaplan, S. S. Chemosphere 2007, 68, 1846-1853.

(27) Li, F. B.; Li, X. Z.; Ao, C. H.; Hou, M. F.; Lee, S. C. Appl. Catal., B 2004, 54, 275-283.

(28) Parkhomchuk, E. V.; Vanina, M. P.; Preis, S. Catal. Commun. 2008, 9, 381-385.

(29) Priya, M. H.; Madras, G. J. Photochem. Photobiol., A 2006, 179, 256-262.

(30) Sivalingam, G.; Priya, M. H.; Madras, G. Appl. Catal., B 2004, $51,67-76$

(31) Adán, C.; Carbajos, J.; Bahamonde, A.; Oller, I.; Malato, S.; Martínez-Arias, A. Appl. Catal., B 2011, 108-109, 168-176.

(32) Bozzi, A.; Yuranova, T.; Mielczarski, J.; Kiwi, J. New J. Chem. 2004, 28, 519-526.

(33) Cabeza, A.; Gómez-Alcantara, M. M.; Olivera-Pastor, P.; Sobrados, I.; Sanz, J.; Xiao, B.; Morris, R. E.; Clearfield, A.; Aranda, M. A. G. Microporous Mesoporous Mater. 2008, 114, 322-336.

(34) Man, T. Y.; Lin, X. Z.; Zhang, X. J.; Yuan, Z. Y. New J. Chem. 2010, 34, 1209-1216.

(35) Ma, T. Y.; Zhang, X. J.; Yuan, Z. Y. Microporous Mesoporous Mater. 2009, 123, 234-242.

(36) Moulder, J. F.; Stickle, W. F.; Sobol, P. E.; Bomben, K. D. Handbook of X-ray Photoelectron Spectroscopy; Perkin-Elmer Corporation: Eden Prairie, MN, 1992.

(37) Paszternak, A.; Felhosi, I.; Paszti, Z.; Kuzmann, E.; Vertes, A.; Kalman, E.; Nyikos, L. Electrochim. Acta 2010, 55, 804-812. 